\title{
Construction and Validation of Next Generation Teacher Educator Competency Scale [NGTECS]
}

\author{
Prakasha G S \\ School of Education, CHRIST (Deemed to be University), Bangalore, 560029, India
}

Received May 6, 2020 ; Revised June 12, 2020; Accepted July 7, 2020

Copyright $\mathrm{C} 2020$ by authors, all rights reserved. Authors agree that this article remains permanently open access under the terms of the Creative Commons Attribution License 4.0 International License

\begin{abstract}
The article presented here is a part of the major research project conducted in India from 2016 through 2020. Teacher education in India in the last six decades underwent many reforms in terms of policies, assessment, field experience patterns, and training pedagogy. Teacher educators invariably implemented all the suggested changes. However, it lacked the rigour in implementation. At the same time with the advancement of technology, the student population is native to technology and had newer attitudes towards learning. Researcher felt that, the Teacher educators competencies are to be revisited and may come up with a new list of competencies which are helpful to the next generation. It is with this intent this major research project was planned. The purpose of the project was to come up with the list of competencies for teacher educators which are helpful for training the next generation teacher trainees and to measure those competencies. Therefore, the study resorted to adopt exploratory research design. This article explains the step wise procedure on construction of next generation teacher educator competency scale. It also explains the procedures of validity and reliability established for the scale. The study brought out a Likert type of scale to measure next generation teacher educator competency and has simple administration procedures. The scale was found to be highly reliable based on Cronbach's alpha internal consistency coefficient. Though the study is exploratory in nature, yet confirmatory factor analysis was carried out and is found to be in agreement with the evolved factors. The scale may be used to measure the extent to which the next generation teacher educator competencies are possessed by a teacher educator.
\end{abstract}

Keywords Competency, Next-generation, Teacher Educator

\section{Introduction}

The educational goals of a society undergo periodic changes in accordance to the changing social reality and aspirations. The learning expectations from 21 st century students are diverse; ranging from skills that would help them enhance their own personality to skills that would help them contribute globally. Students in the past and in the present times, not only think about different things but also think differently. The emerging Generation who are largely influenced by mobile technology and virtual reality, have different ways of learning. These ways are not just different from how their parents or teachers learnt, but are also different from their immediate generation behind them. Unfortunately, schools invest in "building" better schools rather than creating a flexible learning environment and providing teachers access to training that can help them cater to changing learner needs. According to the interviews conducted by the Pew Internet and American Life Project of over 900 Internet stakeholders and critics, learners might not have to remember as much in the future, but they will have better critical and analytical skills. As time spent on memorisation would have reduced, learners would now have the time to learn new things.

Teachers may prepare themselves to meet the needs of all learners in an expanding educational space, owing to efforts that try to make education accessible to all. Teachers may also develop themselves to cater to the learners as future citizens of the world, to reduce socioeconomic divide. Students do not remain the only seekers of education. Internet technologies allow individuals across the world to have access to knowledge and skill training, as educators can connect to them through the Internet. Developing teacher-created virtual networks allow teachers to learn from one another and reduce bureaucratic control over staff development $[1,2]$.

In the future, at least three decades from now, interactive media environments and interactive learning games would influence learners' cognitive skills, which would require 
teachers to adopt new methods and teach differently. Developments in cognitive science inform us about various new innovative methods that could be in teaching. Teacher education is crucial to ensure the personal transformation of the teacher; to ensure that teachers are aware of what being an 'ideal' teacher means with changing times and to be inspiring and value based. Unfortunately there is a lack of recognition of the agency of a teacher and the role a teacher plays in the transformation of society [10].

India has one of the largest education systems in the world [12]. Various commissions and committees have acknowledged and recognised the importance of training teachers and improving teacher education, which is reflected in the teacher education policy in India, like the Kothari Commission (1966), Chattopadhyay Committee (1985), National Policy for Education (NPE 1986/92), National Curriculum Framework (NCF, 2005), National curriculum framework for teacher education (NCFTE 2009), and the draft National education policy (NEP 2019).

The onus of transforming a learner to identify their own strengths, develop themselves and attain expected lies on the teacher. Research affirms that teachers continue to be the most powerful influence on student success [3, 4]. The effectiveness of teaching lies in the profile of classroom instruction.

It is essential for teachers to develop their knowledge and skills and explore various teaching methods. Studies on teacher competencies stress on the teaching role of the teacher in the classroom over the competencies of teachers. Teacher competencies, however, have been broadening in the fields of reform studies, teacher education development and scientific results of educational science. There is a need for teachers' professional development to be redefined for sustainability in education. The goals and aims of education change rapidly with the demands of the new era, which demand more capability. This effects the education system directly. Teachers operate the education system and hence require efficient and powerful competencies. These competencies shall be reviewed from time to time so that the competencies can be redefined based on the development of life and education in the social context [5].

Education, as a discipline strives to reveal systematic and scientific results in order to meet the needs of individuals and society. Studies may be conducted to develop sub-systems in the educational system to cater to the needs and requirements. Teacher training is one such sub-system and is also responsible for the management of the educational system. Teacher training is conducted to fulfil the basic purpose of effective planning, management, development and administration of the educational system by empowering the teachers with certain competencies. Teachers' competencies have narrow dimensions like teacher planning, implementation, curriculum assessment and standards for the school or curriculum. The competencies are related to the duties of the teacher in the school. In this perspective, teachers' competencies need to be discussed through other dimensions as well like the field experiences, research, curriculum, lifelong learning, socio-cultural, emotional, communication, information and communication, and environmental competencies to bring about overall development of teachers [5].

India in the past few decades invested on the in-service teacher development through institutes like National council of educational research and training (NCERT), District institute for education and training (DIET), Department of state educational research and training (DSERT), and State council of educational research and training (SCERT). Though teacher education also underwent many reforms by policies but was remained a failure at the ground level. Therefore, in order to install newer teacher competencies, the teacher education may identify the competencies required of teacher educators to train the next generation trainee teacher.

Other than the developments in various fields, consistent changes in human lives make it difficult to define teacher competencies effectively. For example, environmental competencies might not have been discussed in the past twenty to thirty years for teachers. However, the problems faced by people due to the environment have caused an increase in interest in people towards the environment. This has resulted in environmental issues being included in education and teaching. Therefore, daily life and developments in society which are based on the needs of people influence the teaching profession and hence affect teacher competencies too [5].

Defining competencies and developing them amongst teachers is essentially the work of teacher educator and the Teacher education institutes may ensure that the teacher educators may have these newer competencies and if not they may plan for identifying the competencies required of next generation teacher educators so that in turn they train the next generation of teachers well to cater to the needs of the future student generation.

\subsection{Objectives of the Study}

The study aims at constructing next generation teacher educator competency scale by establishing validity and reliability.

\subsection{Operational Definitions}

Teacher: In the present study, teacher is a person who helps students to acquire knowledge, competence or virtue and who is working as a teacher in the 21 st century to the students of age group between 14 to 16 years.

Teacher Educator: In the present study, teacher educator is a person who helps to acquire knowledge, competence or virtue to the students of secondary school teacher training programme (B.Ed) and who is working as a teacher educator in the 21 st century.

Next Generation Competence: In the present study, next generation competence is possessing the skills, knowledge, attitudes, and abilities to successfully execute the job required in the given context, and incorporates dispositions, 
pedagogical attributes, perspectives and practices by teacher and teacher educator of the 21 st century

Competency: It is the ability to execute teaching job successfully or efficiently by teacher or teacher educator of the 21 st century

\section{Materials and Methods}

The present study adopted exploratory research design to construct the intended next generation teacher educator competency scale. Researcher had used both primary research method and secondary research method of the exploratory research design.

\subsection{Primary Research Method}

Investigator visited the selected B.Ed colleges to collect the research data from Teacher educators working in those B.Ed colleges. Investigator put forth the following question to each teacher educator; what professional changes they look forward from the current or next generation teacher educators to train the next generation teacher trainees? The suggested changes from B.Ed college faculty members were noted down and were thoroughly analysed to bring out the competencies required of a next generation teacher educator. Researcher also conducted a consultative workshop at national level on Competencies required of a next generation teacher educators. Reflections and discussions held during the consultative workshop were noted down. The collected data from these were analysed and researcher came out with a list of 148 teacher educator competencies. This process of data collection is also known as crowdsourcing. Crowdsourcing data usually will have a strong agreement on the data culled out due to the participation of more resource persons $[6,7]$.

\subsection{Secondary Research Method}

Researcher reviewed several national and international research literature to find out the competencies required of a next generation teacher educator. Researcher picked up the competencies based on its frequency of occurrence in past research studies and bearing in mind the competencies identified during the crowdsourcing research method. Researcher had compiled the data obtained in primary and secondary research method and developed a list of next generation competencies for teacher educators.

\subsection{Scale Development}

The data obtained from primary research method and secondary research method were analysed and grouped into six major competences in consultation with the experts. The six major competences are; Knowledge competence, Information and communication technology competence, Pedagogic competence, Assessment competence, Professional and Personal competence, Research competence. Each of these competences had a list of competencies. Researcher had constructed test items for all the competencies listed in each competence and in total 78 test items were constructed as a first draft. Researcher had adopted Likert type rating scale for each of these items [11]. After subjecting these items to pilot study and based on the results of pilot study the scale has been revised and 60 items were retained in the final form of the scale (See Appendix).

\subsection{Validity}

Face validity of the test items were carried out by the researcher and the supervisor of the major research project. Content validity has been established with the help of panel of experts. Construct validity has been established during the pilot study by administering the constructed instrument.

\subsection{Sample of the Study}

The population of the study is Teacher educators teaching in secondary teacher training (B.Ed) colleges in India. The sample of the study is Teacher educators teaching in secondary teacher training colleges (B.Ed) across India. The study randomly selected 100 teacher educators to be part of the sample.

\section{Results and Discussion}

The test items constructed in the Likert type of scale were administered to the sample of the study to establish validity and reliability. The data obtained has been fed into SPSS software and is subjected to statistical analysis. The study subjected the pilot study data to statistical tests such as confirmatory factor analysis and Cronbach's alpha internal consistency test.

\subsection{Cronbach's Alpha Test}

Table 1. Cronbach's alpha

\begin{tabular}{|c|c|}
\hline Cronbach's Alpha & $\mathrm{N}$ \\
\hline 0.92 & 100 \\
\hline
\end{tabular}

Cronbach's Alpha value of 0.92 in table 1 is considered as a highly reliable measure. Cronbach Alpha value of 0.7 and above is considered reliable [8]. Therefore the next generation teacher competency scale is found to be highly reliable.

\subsection{Confirmatory Factor Analysis}

As the set of competencies were formed under 6 different competences with the help of panel of experts, the data collected were subjected to confirmatory factor analysis to find the major factors contributing to the next generation teacher educator competency scale (NGTECS). The result of the confirmatory factor analysis (CFA) is presented in the table 2 . 
Table 2. Confirmatory Factor Analysis

\begin{tabular}{|c|c|c|c|c|c|c|}
\hline \multirow{2}{*}{ Factors } & \multicolumn{3}{|c|}{ Initial Eigenvalues } & \multicolumn{3}{c|}{ Extraction Sums of Squared Loadings } \\
\cline { 2 - 7 } & Total & Variance \% & Cumulative \% & Total & \% of variance & Cumulative \% \\
\hline 6 & 31.920 & 40.924 & 60.551 & 21.531 & 27.604 & 56.356 \\
\hline
\end{tabular}

From table 2 it is clear that, the 6 identified competences of NGTECS are contributing $60.551 \%$. That is the variation in NGTECS is explained by the 6 competences is up to $60.551 \%$. Figure 1 is the scree plot of confirmatory factor analysis. It plots the Eigen values against the factor numbers. Scree plot is clearly showing 4 components distinctly contributing to NGTECS and the remaining two are close to one another showing the potential to be the contributing factors in sequence. From the seventh factor onwards you can see that the line is almost flat indicating that the factors account for the smaller and smaller amount of the total variance.

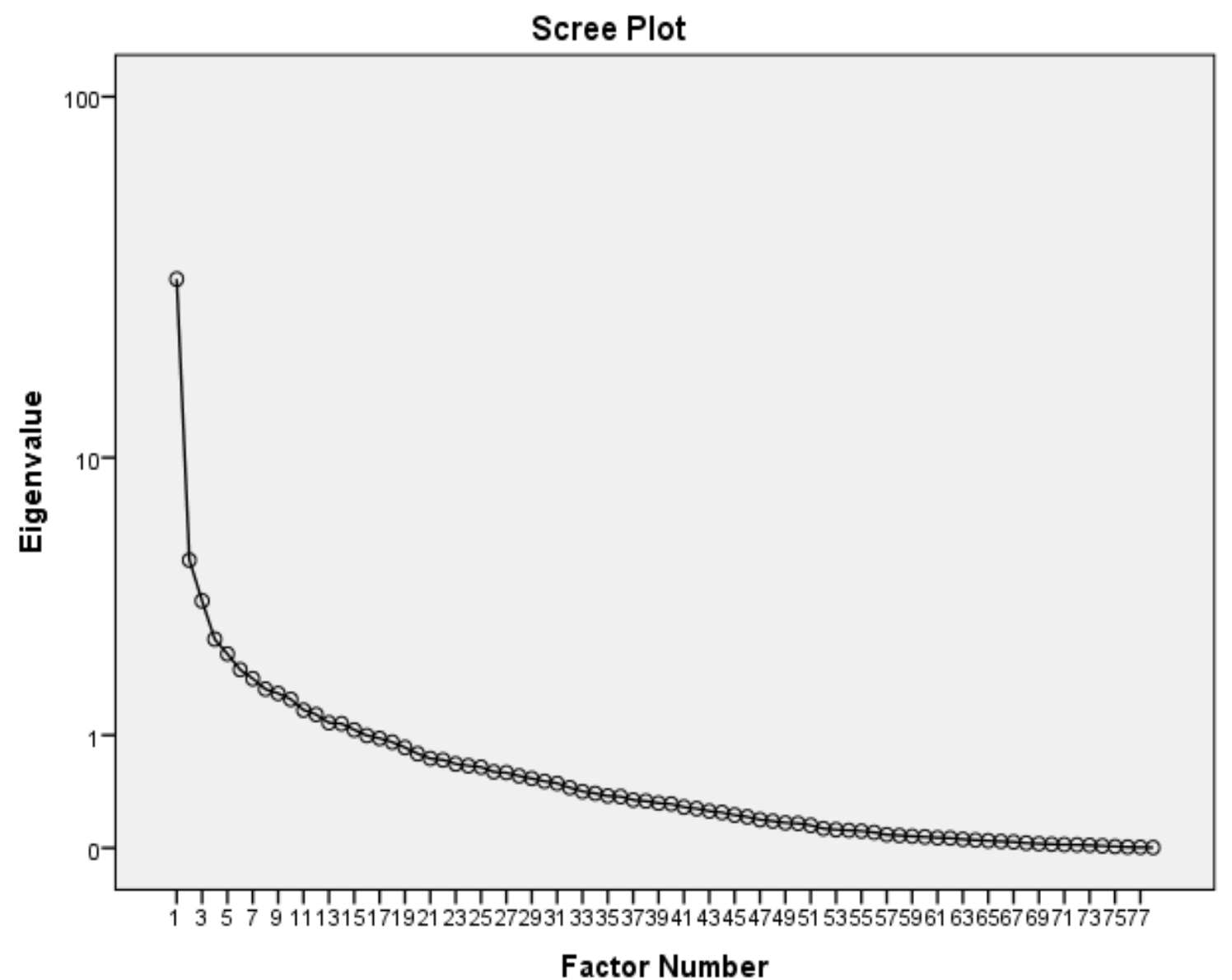

Figure 1. Scree Plot of CFO

Table 3. KMO and Bartlett's Test

\begin{tabular}{|l|c|c|}
\hline \multicolumn{2}{|c|}{ Kaiser-Meyer-Olkin Measure of Sampling Adequacy. } & .750 \\
\hline \multirow{3}{*}{ Bartlett's Test of Sphericity } & Approx. Chi-Square & 8082.227 \\
\cline { 2 - 3 } & df & 3003 \\
\cline { 2 - 3 } & Sig. & .000 \\
\hline
\end{tabular}

From table 3, the Kaiser-Meyer-Olkin (KMO) measure of sampling adequacy value of 0.750 indicates a higher level of sampling adequacy and reiterates that the proportion of variance is explained by the 6 competences underlying NGTECS. As the Bartlett's test of sphericity $\mathrm{p}$ value is less than 0.05 , it indicates that the factor analysis is appropriate for the data under study. 
Though the study is an exploratory research, the statistical analysis by using Cronbach's alpha was found to be highly reliable. Though the study also tested the constructed instrument on confirmatory factor analysis, it is not necessary in an exploratory research design and yet CFA was also $60.5 \%$ in agreement with the factors chosen for the study. The exploration of the teacher educator competencies was mostly focused on their academic engagement and has not looked into certain general social responsibility aspects of the teacher educator. Study did not focus on social responsibility factors like sustainability, conservation of resources, and environmental issues. Future researchers may consider some of these factors while developing a comprehensive competency package for teacher educators [9]. The research design followed for the study is presented in figure 2 .

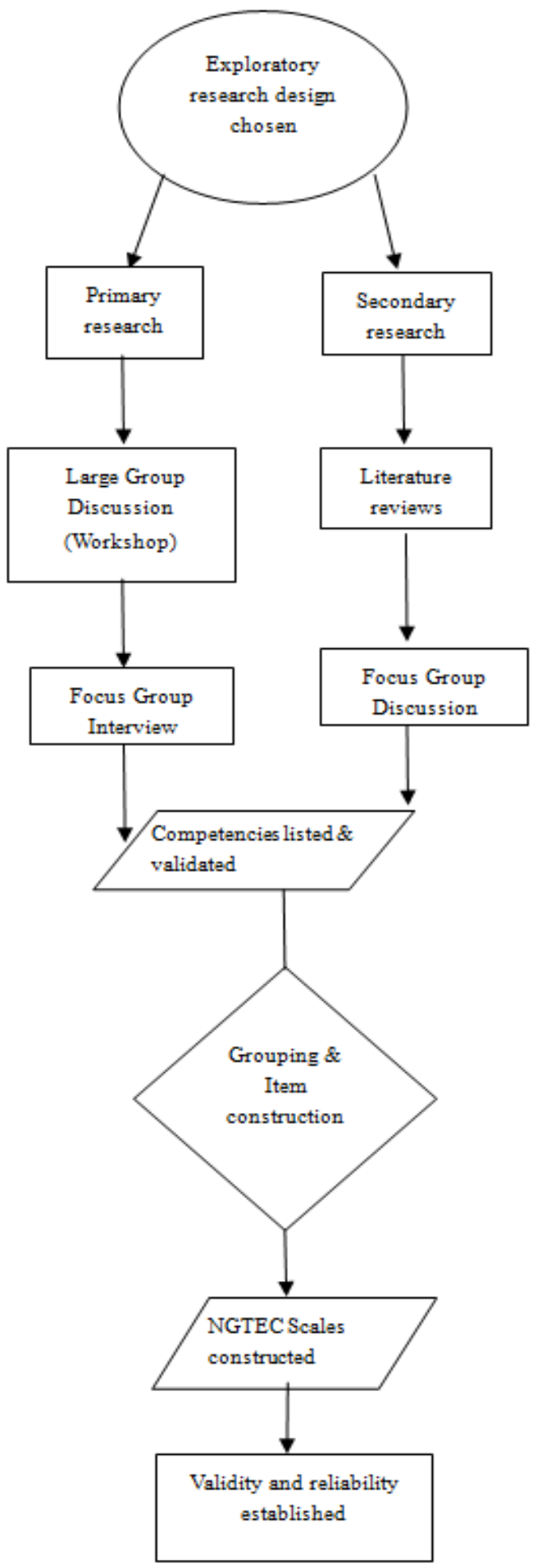

Figure 2. Study design 


\section{Conclusions}

Teacher Education in India is facing many practical difficulties in spite of several quality improvement reforms. However the present study looked at the demands of the next generation teaching and the capability of existing teacher educators and eventually decided to identify the competencies required of next generation teacher educators. The competencies were evolved from an exploratory research design and it also planned to measure the competencies by constructing a competency measurement scale. The study has evolved with a next generation teacher educator competency scale and was able to establish its validity and reliability of the scale. The constructed instrument can be used by the teacher education institutes to measure the extent to which their teacher educators are skilled with next generation competencies. It can also be used in the process of teacher educator recruitments. Nevertheless it could be used to plan faculty development programme (FDP) for strengthening various competencies listed in the study.

\section{Acknowledgments}

I am grateful to the management of CHRIST (Deemed to be University) for providing the opportunity, encouragement, and financial support in carrying out this study.

\section{Appendix}

Next Generation Teacher Educator Competency Scale [NGTECS].

Instructions: The following are the statements related to next generation teacher educator competencies. Teacher educator is expected to respond to each statement on a five point rating scale i.e. SDA- Strongly Disagree (1), DADisagree (2), U- Undecided (3), A-Agree (4), and SAStrongly Agree (5)

1. I have mastery over the subject which I teach.

2. I search online learning resources for students and communicate the same through an email

3. I plan a set of learning materials to support specific learning objectives as per my instructional plan.

4. I am able to use wide variety of formative testing tools to assess student learning.

5. I uphold the Institutional values and conform to societal values always

6. I can find solutions to the problems at work situation through action research.

7. I can analyse and evaluate an issue objectively to draw conclusion.

8. I am able to teach using computer/laptop with various software packages/ intranet/ internet.
9. I usually refer and apply teaching-learning principles, pedagogies, and class management strategies to my class.

10. I am able to use wide variety of summative testing tools to assess student learning.

11. I am accountable to my professional work, my college, and to society on the whole.

12. I am aware and often read various academic reading materials like Journals, Magazines, Newspaper columns, Text books, reference books, research abstracts, and research thesis.

13. I have knowledge on technical vocabulary to be used pertaining to the teaching-subject.

14. I am aware of and use various e-teaching strategies and techniques.

15. I am aware of various teaching models and also use them in my class room instruction.

16. I bear in mind the guidelines of Norm Referenced Testing and Criterion Referenced Testing while constructing tests and assessment for my students.

17. I plan, create, and control all the academic activities.

18. I write scholarly academic articles as a part of my profession.

19. I have knowledge on other subjects related to my teaching-subject.

20. I prepare, use and aware of various e-presentation techniques.

21. I use the medium of instruction and spoken language proficiently.

22. I complete formative and summative assessment, class work correction, and other assigned work on time.

23. I am usually available and approachable to students, colleagues, and management staffs.

24. I am aware of various research methods and be able to apply to research problems.

25. I am up-to-date with the knowledge of my teaching subject, related subjects, and current affairs.

26. I can type on a computer keyboard at a good speed.

27. I am aware of various learning activities and also be able to use them in my class.

28. I am able to interpret the exam/test results appropriately.

29. I am able to manage success and failures in my profession.

30. I am able to choose a suitable statistical analysis to test a research hypothesis.

31. I am aware of variety of knowledge sources that supports my classroom teaching and learning.

32. I use and I am aware of various e-learning platforms.

33. I give timely reinforcement to students and colleagues appropriately at various contexts.

34. I have the skill of constructing answer scheme/ answer key for assessment. 
35. I extend my services on humanitarian grounds.

36. I reflect and write critical reports on various issues and topics of education.

37. I use and I am aware of various knowledge resources.

38. I am able to adopt newer Gadgets to support my teaching and learning.

39. I give appropriate home assignment for drill and practice of the learning.

40. I have the skill of developing and using various marking scheme techniques.

41. I usually develop a cordial relationship among my colleagues.

42. I have a considerable proficiency in research process.

43. I have knowledge on the process of developing and strengthening one's teaching skills, instincts, and abilities.

44. I am able to use and be aware of various media-assisted teaching.

45. I am able to engage students productively towards learning.

46. I am able to give accurate feedback on students' performance to the student, parents, and management.

47. I am able to use and be aware of various data collection techniques.

48. I am aware of ways and the processes of knowing.

49. I am able to use and be aware of various e-resources for teaching and learning.

50. I am able to perform and undertake several tasks in terms of planning, execution and achieving good results.

51. I am able to write discussion summaries, anecdotes, and observations.

52. I use social media to exchange information and to develop professional contacts.

53. I have the skill of questioning to develop the lesson and to test student learning.

54. I am able to value the answer scripts, assignments, and project work accurately without any bias and on time.

55. I am able to construct appropriate research tools to carry out research.

56. I am able to carry out the process of valuation through online and electronic devices.

57. I am able to deliver accurate knowledge of the subject matter with appropriate methods, examples, teaching-aids, and technological-aids.

58. I am able to administer standardised tools to my students and interpret the results.

59. I am able to use and be aware of various diagnostic testing techniques.

60. I am able to work cordially with my colleagues on various institutional and academic work.

\section{REFERENCES}

[1] Reeves, P. and J. Berry (2008), "Preparing, Developing and Credentialing K-12 School Leaders: Continuous Learning for Professional Roles", National Council of the Professors of Educational Administration.

[2] Schleicher, A. (2012), Ed., Preparing Teachers and Developing School Leaders for the 21st Century: Lessons from around the World, OECD Publishing. http://dx.doi.org/10.1787/9789264xxxxxx-en

[3] Babu, S., \& Mendro, R. (2003). Teacher accountability: HLM-based teacher effectiveness indices in the investigation of teacher effects on student achievement in a state assessment program. Presented at the annual meeting of the American Educational Research Association (AERA), Chicago, IL, April.

[4] Sanders, W. L., \& Rivers, J. C. (1996). Cumulative and residual effects of teachers on future student academic achievement. Knoxville, TN: University of Tennessee Value-Added Research and Assessment Center. Retrieved from

http://heartland.org/policy-documents/cumulative-and-resid ual-effects-teachers-future-student-academic-achievement

[5] Selvi, Kıymet. (2010). Teachers' Competencies. Cultura. International Journal of Philosophy of Culture and Axiology. 7. 167-175. 10.5840/cultura20107133.

[6] McDuff, D. J., Kaliouby, R. E., \& Picard, R. W. (2012). Crowdsourcing Facial Responses to Online Videos. Transactions on Affective Computing, In Press

[7] Morris, R. R., \& Picard, R. (2012). Crowdsourcing Collective Emotional Intelligence. Proceedings of Collective Intelligence, Cambridge, MA.

[8] Nunnally, J. C., \& Bernstein, I. H. (1994). Psychometric theory (3rd ed.). New York: McGraw-Hill.

[9] Ash, K. (2012). Competency-based schools embrace digital learning. Education Week, 6(1), 36-41.

[10] Avery, Dennis Van. "Futuristic and education." Educational leadership, February (1980):441-442.

[11] Bridges, David. "School-based teacher education." Eds. David Bridges \& Trevor Kerry. Developing teachers professionally. London: Routledge. 1993. 51-66.

[12] Gupta, I. (2014, June 16). India has one of the largest education systems in the world. IBEF blog. https://www.ibef.org/blogs/india-has-one-of-the-largest-edu cation-systems-in-the-world 